\title{
A prospective "oversizing" strategy of the Edwards SAPIEN bioprosthesis: Results and impact on aortic regurgitation
}

\author{
Mariam Samim, BSc, ${ }^{a}$ Pieter R. Stella, MD, PhD, ${ }^{\mathrm{a}}$ Pierfrancesco Agostoni, $\mathrm{MD}, \mathrm{PhD},{ }^{\mathrm{a}}$ \\ Jolanda Kluin, MD, PhD, ${ }^{b}$ Faiz Ramjankhan, MD, ${ }^{\mathrm{b}}$ Gertjan Sieswerda, MD, PhD, ${ }^{\mathrm{a}}$ \\ Ricardo Budde, MD, PhD, ${ }^{a}$ Marijke van der Linden, RN, ${ }^{a}$ Francis Juthier, MD, ${ }^{\mathrm{c}}$ Carlo Banfi, MD, ${ }^{\mathrm{c}}$ \\ Christopher Hurt, MD ${ }^{\mathrm{c}}$ Morsal Samim, BSc, ${ }^{\text {a }}$ Marieke Hillaert, MD, ${ }^{\mathrm{a}}$ Lex van Herwerden, MD, PhD, ${ }^{\mathrm{b}}$ \\ Michel E. Bertrand, MD, ${ }^{\mathrm{c}}$ Pieter A. M. Doevendans, MD, PhD, ${ }^{\mathrm{a}}$ and Eric Van Belle, MD, $\mathrm{PhD}^{\mathrm{c}}$
}

\begin{abstract}
Objective: Moderate to severe aortic regurgitation is occurring in $20 \%$ to $30 \%$ of cases after transcatheter aortic valve implantation.

Methods: The purpose of the study was to investigate the impact of a prospective policy of "oversizing" the Edwards SAPIEN bioprosthesis (Edwards Lifesciences LLC, Irvine, Calif) relative to the diameter of the aortic annulus on the rate and severity of aortic regurgitation in 28 consecutive patients initially considered eligible for transcatheter aortic valve implantation on the basis of angiography, multislice computed tomography, and transthoracic echocardiography. This policy included the systematic use of transesophageal echocardiography to exclude borderline patients and the modification of the procedure to use the larger device possible. The results were studied on an individual patient basis.
\end{abstract}

\begin{abstract}
Results: Because 6 of 28 patients ( $21 \%$ ) had an annulus diameter greater than $24 \mathrm{~mm}$ by transesophageal echocardiography, 22 patients underwent implantation of the Edwards SAPIEN prosthesis. In 6 of 22 patients, the procedure was adapted to follow our "oversizing" policy. As a result, the "prosthesis/annulus cover index" was $12.4 \% \pm 4.3 \%$. The procedure was successful in 21 of 22 patients $(95 \%)$, and 18 patients were available for echocardiography at 1 month. Although a moderate to severe aortic regurgitation was observed pretreatment in 4 of 18 patients $(22 \%)$, it was no longer the case at 1 month $(0 / 18,0 \% ; P=.03)$. The improvement was secondary to a disappearance of the aortic regurgitation in all 7 patients with a significant aortic regurgitation at pretreatment, whereas the new aortic regurgitations appearing in 5 of the 11 patients with no aortic regurgitation at pretreatment were only mild aortic regurgitations.
\end{abstract}

Conclusions: In patients with a successful implantation of an Edwards SAPIEN valve, a simple "oversizing" policy based on a systematic use of transesophageal echocardiography and modification of the procedure may prevent the occurrence of moderate and severe aortic regurgitations. (J Thorac Cardiovasc Surg 2013;145:398-405)

Transcatheter aortic valve implantation (TAVI) is a developing technique to treat patients with aortic stenosis. ${ }^{1,2}$ Because questions remain concerning safety and durability, its use currently is limited to patients contraindicated or at very high risk for conventional aortic valve replacement.

After TAVI, a moderate to severe paravalvular aortic regurgitation (AR) can occur in approximately $20 \%$ to $30 \%$ of cases after implantation. ${ }^{3,4}$ Although this is usually

From the Departments of Cardiology ${ }^{\mathrm{a}}$ and Thorax Surgery, ${ }^{\mathrm{b}}$ University Medical Center, Utrecht, The Netherlands; and Department of Cardiology, ${ }^{\mathrm{c}}$ University Hospital, Lille, France.

Disclosures: Dr Sieswerda reports receiving lecture fees from Actelion. The other authors have nothing to disclose with regard to commercial support.

Received for publication Aug 14, 2011; revisions received Nov 20, 2011; accepted for publication Dec 14, 2011; available ahead of print Feb 29, 2012.

Address for reprints: Eric Van Belle, MD, PhD, EA 2693, University Lille Nord de France and Department of Cardiology, CHRU de Lille, 59037 Lille Cedex, France (E-mail: ericvanbelle@aol.com).

0022-5223/\$36.00

Copyright (c) 2013 by The American Association for Thoracic Surgery

doi:10.1016/j.jtcvs.2011.12.067 considered as acceptable in the elderly population, it is a limitation to a broader use of this technique. Implantation of an undersized prosthesis has been proposed as a major cause of this issue..$^{3,5-7}$ Although it is usually recommended to "oversize" the implantation of the Edwards SAPIEN bioprosthesis (Edwards Lifesciences LLC, Irvine, Calif) relative to the annulus diameter as measured by transesophageal echocardiography (TEE) by 2 to $4 \mathrm{~mm}$, this rule is not strictly applied, particularly in patients with a large annulus or borderline vascular accesses. ${ }^{3}$ To date, the benefit of a strict "oversizing" policy on the severity of AR has never been investigated.

When starting our TAVI program with the Edwards SAPIEN bioprosthesis, we decided to implement a prospective policy of systematic "oversizing" the bioprosthesis relative to the diameter of the aortic annulus and to test its impact on the rate and severity of AR. This issue was studied by means of serial 2-dimensional transthoracic echocardiography (TTE) Doppler cardiography performed before the procedure, before discharge, and at 1 month. 

Abbreviations and Acronyms
$\mathrm{AR}=$ aortic regurgitation
AVI $=$ aortic valve implantation
$\mathrm{LV}=$ left ventricular
$\mathrm{TA}=$ transapical
TAVI $=$ transcatheter aortic valve implantation
TEE $=$ transesophageal echocardiography
$\mathrm{TF}=$ transfemoral
TTE $=$ transthoracic echocardiography

\section{MATERIALS AND METHODS \\ Patient Population and Selection}

Patients with severe aortic stenosis considered to be at high or prohibitive surgical risk were considered to undergo TAVI with the Edwards SAPIEN valve at University Medical Center, Utrecht, The Netherlands. Consensus was achieved between cardiologists and cardiac surgeons regarding the surgical risk, and all patients provided informed written consent.

To determine the initial eligibility for TAVI and to choose between the transfemoral (TF) aortic valve implantation (AVI) or the transapical (TA)AVI approach, all patients underwent coronary angiography, aortobifemoral angiography, multislice computed tomography, and TTE. Potential candidates for TAVI demonstrated symptomatic degenerative aortic stenosis with at least New York Heart Association class 2 symptoms and an aortic valve area of $1.0 \mathrm{~cm}^{2}$ or mean gradient greater than $40 \mathrm{~mm} \mathrm{Hg}$ or peak gradient greater than $80 \mathrm{~mm} \mathrm{Hg}$. All candidates were contraindicated for conventional surgery or considered a high surgical risk with an operative mortality risk of greater than $20 \%$ as assessed by at least 2 cardiovascular surgeons and 2 cardiologists. ${ }^{8}$

Patients were excluded from TAVI if they had at least 1 of the following: (1) aortic annulus diameter less than $16 \mathrm{~mm}$ or greater than $24 \mathrm{~mm}$ by TTE; (2) congenital unicuspid or bicuspid valve; (3) noncalcified valve; (4) untreated clinically significant proximal coronary artery disease; (5) severe left ventricular (LV) dysfunction less than $20 \%$; or (6) hemodynamic instability requiring inotropic support.

All patients were considered as potential candidates for TF-AVI unless they had at least 1 of the following: (1) mobile aortic arch atheroma greater than $5 \mathrm{~mm}$ or (2) iliofemoral dimensions, morphology, or calcifications that would preclude insertion of a $22 \mathrm{~F}$ sheath or $24 \mathrm{~F}$ introducer sheath based on a detailed assessment of aortobifemoral angiography and multislice computed tomography, in which case they were considered for TA-AVI.

On the basis of this initial selection process, 28 patients were considered potential candidates. All patients underwent TEE before the final planning of the procedure. As part of our "oversizing" policy (see below), those with an annulus diameter greater than $24 \mathrm{~mm}$ by TEE were further excluded and did not undergo the procedure.

\section{Choice of Bioprosthesis Size and "Oversizing" Policy}

The Edwards SAPIEN transcatheter heart valve is a catheter-delivered heart valve that is composed of a stainless-steel balloon-expandable stent, with an integrated trileaflet tissue valve and a polyethylene terephthalate fabric cuff. The valve tissue is made from 3 equal sections of bovine pericardium treated with a proprietary tissue treatment. During the time of the study, the bioprosthesis was available in 2 sizes $(23$ and $26 \mathrm{~mm}$ ) and could be delivered through the TF or TA approach.

Our "oversizing" policy for the implantation of the Edwards SAPIEN bioprosthesis was defined as follows: (1) All patients with an aortic annulus greater than $24 \mathrm{~mm}$ by TEE during the final step of the screening were strictly excluded (see above); (2) a 26-mm prosthesis was implanted in all patients with an annulus greater than $21 \mathrm{~mm}$, and the TA approach was used every time it was needed; and (3) in patients with an annulus 21 $\mathrm{mm}$ or less, a 26-mm prosthesis was also implanted every time the balloon predilatation with a $23-\mathrm{mm}$ balloon associated with contrast angiography at maximum balloon inflation demonstrated a significant aortic regurgitation.

To appreciate the degree of "oversizing," the "prosthesis/annulus cover index" expressed as $100 \times$ ([prosthesis diameter - TTE annulus diameter]/ prosthesis diameter) was used, as suggested by Detaint and colleagues. ${ }^{3}$

\section{Transcatheter Aortic Valve Implantation}

The prosthetic stented valve was mechanically crimped on a balloon catheter immediately before implantation. The Retroflex delivery system (Edwards Lifesciences) was used for device implantation. ${ }^{6,9,10}$

$\mathrm{TF}$ and TA-AVI were performed under general anesthesia in the catheterization laboratory as previously described. ${ }^{6,9,10}$ TEE was used for all procedures. Patients were premedicated with aspirin and antibiotics. Heparin was used to maintain an activated clotting time greater than 300 seconds. The activated clotting time was reversed with protamine at the end of the procedure.

For TF-AVI, our technique was similar to that in previously described reports. ${ }^{6,9}$ A surgical cut-down of the femoral arty was performed, and a $14 \mathrm{~F}$ sheath was initially placed. A temporary transvenous electrode was introduced into the right ventricle. Balloon aortic valvuloplasty with a 20- or 23-mm balloon was performed. The balloon-mounted valve was positioned using angiographic techniques and echocardiographic guidance, and subsequently deployed under rapid pacing (180-220 beats/ $\min )$. Exit peripheral angiography was performed to ensure no extravasation of contrast before removal of femoral sheath. The sheath was removed and closed surgically in the operating room by a surgeon immediately postprocedure.

The TA-AVI procedure was performed as previously described. ${ }^{10}$ For the purpose of rapid ventricular pacing, 2 unipolar epicardial pacer wires were secured and tested with a high-output epicardial pacing system to ensure ventricular capture at rates of 180 to 220 beats/min.

Procedural success was defined as the implantation of a functional prosthetic valve within the aortic annulus at the end of the procedure without inlaboratory mortality. Patients received aspirin $(81 \mathrm{mg} / \mathrm{d})$ and clopidogrel $(75 \mathrm{mg} / \mathrm{d})$ indefinitely. Warfarin was substituted for clopidogrel in patients with atrial fibrillation.

\section{Echocardiography Follow-up}

TEE was the final step of the screening process and was performed during the procedure in all patients. TTE was performed during the screening process, pretreatment (last echocardiography study before TAVI), posttreatment (at discharge), and postdischarge (first outpatient clinic visit) using a Philips 5500 or ie33 system (Philips, Eindhoven, The Netherlands). Complete echocardiographic studies were performed for each patient in a standard fashion. Standard parameters were recorded. ${ }^{11}$ By using the parasternal long-axis view and M-mode or 2-dimensional echocardiography, LV diameters, function, and outflow track diameter were obtained.

To assess the severity of aortic stenosis peak aortic velocity, peak instantaneous gradient, mean transaortic gradient, and velocity-time integral were measured. Aortic valve area was estimated using the continuity equation approach. ${ }^{12}$

The color-flow Doppler signal was used to assess aortic regurgitation. According to the European Society of Cardiology guidelines and American Society of Echocardiography recommendations, valvular insufficiency was graded in 5 groups as none $(=0)$, trivial $(=1)$, mild $(=2)$, moderate $(=3)$, or severe $(=4) .{ }^{13,14} \mathrm{~A}$ valvular insufficiency of 2 or greater was considered significant. More specifically, regurgitation was assessed by visual inspection and by using color-flow mapping of the regurgitation jet as described by Zoghbi and colleagues ${ }^{14}$ and Helmcke and colleagues. ${ }^{15} \mathrm{~A}$ 
TABLE 1. Clinical and echocardiography characteristics of the 28 patients

\begin{tabular}{|c|c|c|c|c|c|c|c|}
\hline & Total & $\begin{array}{c}\text { Excluded } \\
\mathrm{N}=6 \\
\end{array}$ & $\begin{array}{c}\text { Included } \\
\mathbf{N}=\mathbf{2 2} \\
\end{array}$ & $P$ & Transfemoral & Transapical & $P$ \\
\hline Age (y) & $80 \pm 8$ & $80 \pm 9$ & $79 \pm 7$ & .71 & $78 \pm 7$ & $80 \pm 8$ & .61 \\
\hline Male, $n(\%)$ & $17(61)$ & $6(100)$ & $11(50)$ & .02 & $4(40)$ & $7(58)$ & .66 \\
\hline BMI $\left(\mathrm{kg} / \mathrm{m}^{2}\right)$ & $27 \pm 6$ & $28 \pm 4$ & $26 \pm 5$ & .04 & $26 \pm 7$ & $26 \pm 4$ & .85 \\
\hline Hypertension, $\mathrm{n}(\%)$ & $21(75)$ & $5(83)$ & $16(73)$ & .58 & $7(70)$ & $9(75)$ & .80 \\
\hline Atrial fibrillation, $\mathrm{n}(\%)$ & $12(43)$ & $2(33)$ & $10(45)$ & .59 & $5(50)$ & $5(42)$ & .70 \\
\hline Diabetes, n (\%) & $5(18)$ & $1(17)$ & $4(18)$ & .93 & $2(20)$ & $2(17)$ & .84 \\
\hline Coronary artery disease, $\mathrm{n}(\%)$ & $16(57)$ & $3(50)$ & $13(59)$ & .69 & $3(30)$ & $10(83)$ & .02 \\
\hline Prior myocardial infarction, $\mathrm{n}(\%)$ & $8(29)$ & $1(17)$ & $7(32)$ & .45 & $2(20)$ & $5(42)$ & .38 \\
\hline Percutaneous coronary intervention, $\mathrm{n}(\%)$ & $11(39)$ & $2(33)$ & $9(41)$ & .73 & $2(20)$ & $7(58)$ & .06 \\
\hline Coronary artery bypass, $\mathrm{n}(\%)$ & $7(25)$ & $1(17)$ & $6(27)$ & .58 & $2(20)$ & $4(33)$ & .64 \\
\hline Cerebrovascular events, n (\%) & $8(29)$ & $1(17)$ & $7(32)$ & .45 & $3(30)$ & $4(33)$ & .87 \\
\hline Peripheral vascular disease, $\mathrm{n}(\%)$ & $3(11)$ & $1(17)$ & $2(9)$ & .61 & $0(0)$ & $2(17)$ & .48 \\
\hline Renal disease, n (\%) & $6(21)$ & $1(17)$ & $5(23)$ & .74 & $2(20)$ & $3(25)$ & .78 \\
\hline COPD, n (\%) & $8(29)$ & $2(33)$ & $6(27)$ & .77 & $3(30)$ & $3(25)$ & .79 \\
\hline \multicolumn{8}{|l|}{ NYHA class, $\mathrm{n}(\%)$} \\
\hline I & $0(0)$ & $0(0)$ & $0(0)$ & & $0(0)$ & $0(0)$ & \\
\hline II & $3(11)$ & $1(17)$ & $2(9)$ & .74 & $1(10)$ & $1(8)$ & .40 \\
\hline III & $22(78)$ & $4(66)$ & $18(82)$ & & $9(90)$ & $9(75)$ & \\
\hline IV & $3(11)$ & $1(17)$ & $2(9)$ & & $0(0)$ & $2(17)$ & \\
\hline Logistic euroSCORE & $21.8 \pm 13.3$ & $23.2 \pm 16.3$ & $21.3 \pm 14.1$ & .81 & $18.1 \pm 15.5$ & $24.1 \pm 12.8$ & .33 \\
\hline LVEF $<35 \%$, n $(\%)$ & $6(21)$ & $1(17)$ & $5(23)$ & .74 & $2(20)$ & $3(25)$ & .78 \\
\hline LV end-diastolic diameter (mm) & $46.2 \pm 4.5$ & $47.5 \pm 5.3$ & $45.7 \pm 5.3$ & .43 & $45.3 \pm 6.1$ & $46.2 \pm 4.8$ & .71 \\
\hline Mean aortic gradient $(\mathrm{mm} \mathrm{Hg})$ & $42 \pm 15$ & $44 \pm 15$ & $41 \pm 16$ & .55 & $40 \pm 16$ & $41 \pm 17$ & .88 \\
\hline Peak aortic gradient $(\mathrm{mm} \mathrm{Hg})$ & $71 \pm 24$ & $73 \pm 21$ & $70 \pm 26$ & .65 & $70 \pm 27$ & $71 \pm 26$ & .95 \\
\hline Aortic valve area $\left(\mathrm{cm}^{2}\right)$ & $0.72 \pm 0.19$ & $0.69 \pm 0.14$ & $0.73 \pm 0.19$ & .25 & $0.73 \pm 0.17$ & $0.73 \pm 0.21$ & .96 \\
\hline Annulus diameter by TTE (mm) & $21.8 \pm 1.2$ & $22.5 \pm 1.1$ & $21.6 \pm 1.3$ & .10 & $21.5 \pm 1.4$ & $21.6 \pm 1.5$ & .91 \\
\hline Annulus diameter by TEE (mm) & $22.6 \pm 1.4$ & $24.9 \pm 0.4$ & $22.0 \pm 1.3$ & .01 & $22.1 \pm 1.3$ & $22.0 \pm 1.3$ & .86 \\
\hline No significant AR, n (\%) & $16(57)$ & $3(50)$ & $13(59)$ & .69 & $5(50)$ & $8(67)$ & .72 \\
\hline Significant AR, n (\%) & $12(43)$ & $3(50)$ & $9(41)$ & & $5(50)$ & $4(33)$ & \\
\hline Aortic regurgitation grade $(0-4)$ & $1.55 \pm 0.95$ & $1.33 \pm 0.82$ & $1.55 \pm 1.01$ & .35 & $1.80 \pm 1.40$ & $1.33 \pm 0.49$ & .29 \\
\hline
\end{tabular}

BMI, Body mass index; COPD, chronic obstructive pulmonary disorder; NYHA, New York Heart Association; euroSCORE, European System for Cardiac Operative Risk Evaluation; $L V E F$, left ventricular ejection fraction; $L V$, left ventricular; $T T E$, transthoracic echocardiography; $A R$, aortic regurgitation. Data are mean \pm standard deviation otherwise stated.

single experienced and independent cardiologist, blinded to the patient clinical status, graded AR.

\section{Statistical Analysis}

Continuous variables were presented as mean \pm standard deviation. Discrete variables were presented as absolute numbers and percentages. For comparison between categoric variables, a chi-square test was used. A 1-way analysis of variance test was used for comparison between continuous variables. A 1-way repeated-measures Friedman test with post hoc analysis was used to evaluate changes over time. Analyses were performed using SPSS 18.0 (SPSS Inc, Chicago, Ill).

\section{RESULTS}

\section{Characteristics of the Study Population and Procedure}

The baseline clinical and echocardiography characteristics of the study population are shown in Table 1. On the basis of the measurement of the annulus diameter by TTE $(<24 \mathrm{~mm}), 28$ patients were initially considered eligible for implantation. On the basis of the subsequent measurement of the annulus diameter by TEE $(>24 \mathrm{~mm})$ during the final step of the screening process, 6 of 28 patients $(21 \%)$ were excluded. By definition and comparison with the remaining 22 patients, the annulus diameter of these 6 patients as measured by TEE was larger $(P=.01$, Table 1). This difference was not detectable by TTE $(P=.10$, Table 1$)$. The 6 excluded patients were male $(100 \%)$ and had a higher body mass index $(P=.04)$ than the remaining 22 patients (Table 1 ).

The medical decision in the 6 patients in whom the TAVI procedure was not performed was as follows: One patient underwent conventional aortic replacement and was alive at 12 months follow-up; 1 patient was eligible for the implantation of a 29-mm CoreValve (Medtronic Inc, Minneapolis, Minn) (the procedure was successful, and the patient died at 7 months follow-up); the last 4 patients underwent conservative medical management ( 2 patients died within 12 months and 2 patients remained alive at 1 year under conservative treatment; 1 of the last 2 patients recently 
TABLE 2. Procedural characteristics and 30-day outcome

\begin{tabular}{|c|c|c|c|c|}
\hline & $\begin{array}{c}\text { Total } \\
\mathbf{N}=\mathbf{2 2} \\
\end{array}$ & $\begin{array}{c}\text { Transfemoral } \\
\mathbf{N}=\mathbf{1 0}\end{array}$ & $\begin{array}{c}\text { Transapical } \\
\mathbf{N}=\mathbf{1 2}\end{array}$ & $P$ \\
\hline $\begin{array}{l}\text { Annulus diameter } \\
\quad(\mathrm{mm}), \text { mean } \pm \mathrm{SD}\end{array}$ & $22.0 \pm 1.3$ & $22.1 \pm 1.3$ & $22.0 \pm 1.3$ & .8 \\
\hline $\begin{array}{l}\text { Aortic valve area }\left(\mathrm{cm}^{2}\right) \\
\quad \text { mean } \pm \mathrm{SD}\end{array}$ & $0.73 \pm 0.19$ & $0.73 \pm 0.17$ & $0.73 \pm 0.21$ & \\
\hline \multicolumn{5}{|l|}{$\begin{array}{c}\text { Prosthesis diameter, } \\
\mathrm{n}(\%)\end{array}$} \\
\hline $23 \mathrm{~mm}$ & $6(27)$ & $3(30)$ & $3(25)$ & \\
\hline $26 \mathrm{~mm}$ & $16(73)$ & $7(70)$ & $9(75)$ & \\
\hline $\begin{array}{c}\text { Cover index, } \%, \\
\text { mean } \pm \mathrm{SD}\end{array}$ & $12.4 \pm 4.3$ & $11.8 \pm 5.5$ & $12.8 \pm 3.2$ & \\
\hline $\begin{array}{l}\text { Successful valvuloplasty, } \\
\text { n }(\%)\end{array}$ & $22(100)$ & $10(100)$ & $12(100)$ & 1 \\
\hline $\begin{array}{l}\text { Successful valve } \\
\text { deployment, } \mathrm{n}(\%)\end{array}$ & $21(95)$ & $10(100)$ & $11(92)$ & \\
\hline $\begin{array}{l}\text { Intraprocedural death, } \\
\mathrm{n}(\%)\end{array}$ & $0(0)$ & $0(0)$ & $0(0)$ & 1 \\
\hline \multicolumn{5}{|l|}{ 30-d outcome } \\
\hline Myocardial infarction & $1(4)$ & $0(0)$ & $1(8)$ & .3 \\
\hline Stroke, n (\%) & $0(0)$ & $0(0)$ & $0(0)$ & 1 \\
\hline Permanent pacemaker & $1(4)$ & $0(0)$ & $1(8)$ &. \\
\hline Mortality, n (\%) & $4(18)$ & $1(10)$ & $3(25)$ & .35 \\
\hline
\end{tabular}

$S D$, Standard deviation. Cover index as $100 \times$ (prosthesis diameter - annulus diameter by TEE/prosthesis diameter).

underwent the implantation of a 29-mm Edwards SAPIEN bioprosthesis).

Among the 22 remaining patients, 12 underwent TA-AVI and 10 underwent TF-AVI. Patients who underwent TAAVI rather than TF-AVI were more likely to have a history of coronary artery disease $(P=.02)$. The other characteristics were not different between the groups.

The relatively low mean annulus diameter $(22.0 \pm 1.3$ $\mathrm{mm}$, Tables 1 and 2) of the population in whom the procedure was performed reflects the exclusion of all patients with an annulus greater than $24 \mathrm{~mm}$ by TEE as part of our "oversizing" policy. Furthermore, in 6 of 22 patients the procedure was modified: In 3 patients with an annulus greater than $21 \mathrm{~mm}$ and suitable for a $22 \mathrm{~F}$ but not for a $24 \mathrm{~F}$ iliofemoral sheath, a TA approach was used. In 3 other patients with an annulus 21 or less by TTE, a 26$\mathrm{mm}$ rather than a $23-\mathrm{mm}$ prosthesis was implanted on the basis of the results of balloon predilatation associated with angiography. As a result, the "prosthesis/annulus cover index" was $12.4 \% \pm 4.3 \%$. Using a 23 -mm prosthesis in the 6 cases mentioned above would have led to a significantly lower "cover index" $(9.9 \% \pm 3.6 \%, P=.02)$.

The procedure was successful in 21 of 22 patients $(95 \%$, Table 2). The patient with unsuccessful valve implant was an 85-year-old man with a history of myocardial infarction, bypass surgery, and peripheral vascular disease. The technical failure was related to the inability to perform appropriate hemostasis at the level of the purse at the apex of the

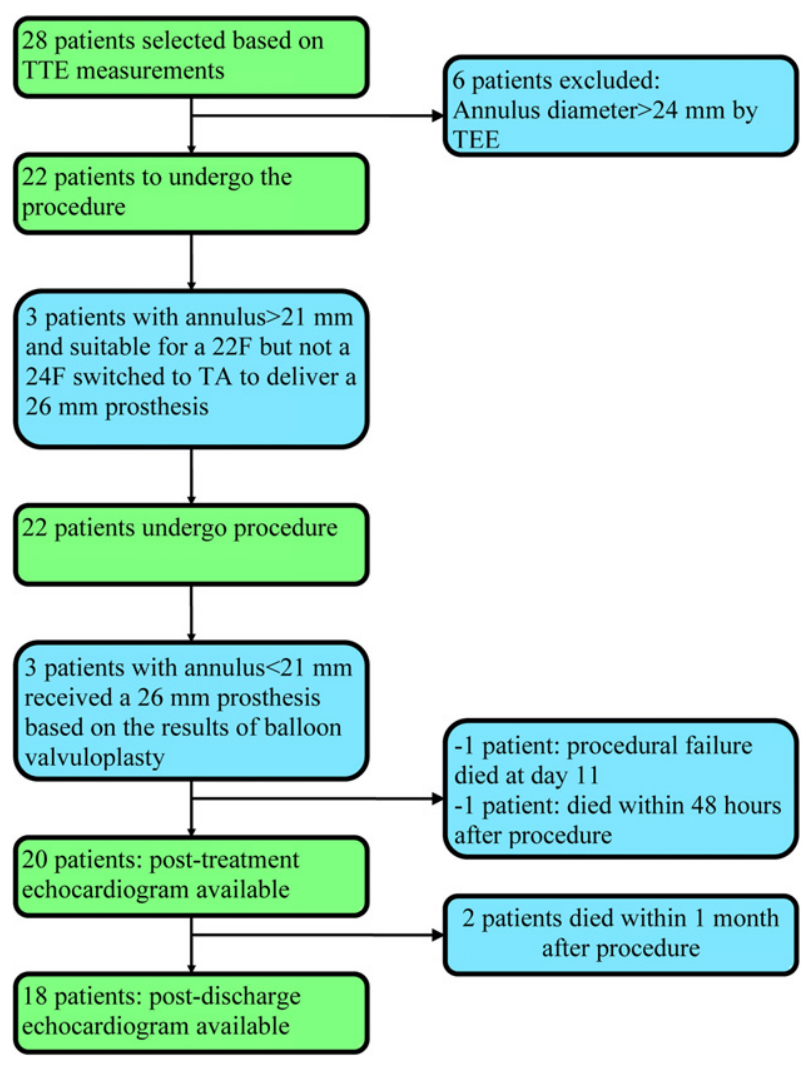

FIGURE 1. Patient flow chart. TEE, Transesophageal echocardiography; $T T E$, transthoracic echocardiography.

left ventricle related to pericardial adherences. The procedure was aborted and converted to open surgery for conventional valve replacement. Although the surgical intervention was successful, the patient died of multiorgan failure on day 11. Another patient died of right ventricular failure secondary to an inferior myocardial infarction in hospital on day 3 from. These 2 in-hospital deaths were observed among the 12 patients who underwent a TA-AVI procedure. No procedural failure and no hospital death were observed in the 10 patients who underwent a TF-AVI procedure. One patient who underwent TA-AVI required a permanent pacemaker implantation before discharge. No rupture of the aortic annulus was observed. No case of severe AR was observed immediately after balloon valvuloplasty by TEE. After implantation of the bioprosthesis, fluoroscopy did not show any distortion of the edges of the stent supporting the valve. Likewise, TEE performed in short axis showed that the circularity of the stent was preserved. Overall, 20 patients $(91 \%)$ underwent a successful procedure and were discharged alive from the hospital.

Within the first 30 days, 2 additional patients died of pulmonary infection in the TA-AVI group (1) and sudden death (1) in the TF-AVI group. No stroke was observed. Eighteen 
TABLE 3. Echocardiography findings during follow-up $(\mathrm{N}=18)$

\begin{tabular}{|c|c|c|c|c|}
\hline & Pretreatment & $\begin{array}{c}\text { Post- } \\
\text { treatment }\end{array}$ & Postdischarge & $P$ \\
\hline LVEF $<35 \%$, n $(\%)$ & $3(23)$ & $2(15)$ & $3(17)$ & .57 \\
\hline $\mathrm{TF}$ & $1(11)$ & $1(11)$ & $1(11)$ & \\
\hline $\mathrm{TA}$ & $2(22)$ & $1(11)$ & $2(25)$ & \\
\hline $\begin{array}{l}\text { LV end-diastolic } \\
\text { diameter }(\mathrm{mm})\end{array}$ & $45.7 \pm 5.9$ & $45.2 \pm 5.5$ & $44.7 \pm 5.3$ & .03 \\
\hline $\mathrm{TF}$ & $45.0 \pm 6.3$ & $44.7 \pm 5.5$ & $44.3 \pm 4.9$ & \\
\hline TA & $46.4 \pm 5.5$ & $45.8 \pm 5.6$ & $45.1 \pm 5.7$ & \\
\hline $\begin{array}{c}\text { Mean aortic gradient } \\
(\mathrm{mm} \mathrm{Hg})\end{array}$ & $42 \pm 17$ & $9 \pm 4$ & $8 \pm 3$ & .00 \\
\hline $\mathrm{TF}$ & $41 \pm 17$ & $12 \pm 4$ & $9 \pm 3$ & \\
\hline TA & $44 \pm 18$ & $7 \pm 2$ & $7 \pm 2$ & \\
\hline $\begin{array}{l}\text { Peak aortic gradient } \\
\quad(\mathrm{mm} \mathrm{Hg})\end{array}$ & $73 \pm 26$ & $17 \pm 6$ & $15 \pm 6$ & .00 \\
\hline $\mathrm{TF}$ & $73 \pm 28$ & $21 \pm 6$ & $17 \pm 8$ & \\
\hline TA & $75 \pm 27$ & $13 \pm 4$ & $13 \pm 4$ & \\
\hline $\begin{array}{l}\text { Aortic valve area } \\
\qquad\left(\mathrm{cm}^{2}\right)\end{array}$ & $0.72 \pm 0.21$ & $1.87 \pm 0.45$ & $1.81 \pm 0.31$ & .00 \\
\hline $\mathrm{TF}$ & $0.73 \pm 0.18$ & $1.87 \pm 0.50$ & $1.86 \pm 0.34$ & \\
\hline TA & $0.71 \pm 0.24$ & $1.88 \pm 0.43$ & $1.75 \pm 0.30$ & \\
\hline $\begin{array}{l}\text { Aortic regurgitation } \\
\text { grade }(0-4)\end{array}$ & $1.56 \pm 1.10$ & $1.17 \pm 0.71$ & $0.89 \pm 0.83 *$ & .03 \\
\hline $\mathrm{TF}$ & $1.78 \pm 1.48$ & $1.22 \pm 0.67$ & $1.11 \pm 0.78$ & \\
\hline TA & $1.33 \pm 0.50$ & $1.11 \pm 0.78$ & $0.67 \pm 0.87$ & \\
\hline
\end{tabular}

All parameters are mean \pm standard deviation, otherwise stated. $P$ reflects the difference among the 3 time points by 1-way repeated measures Friedman test. $L V E F$, Left ventricular ejection fraction; $T F$, transfemoral; $T A$, transapical; $L V$, left ventricular. $* P<.05$ compared with "pretreatment" by post hoc analysis of the Friedman test.

patients were available for echocardiography after discharge (Figure 1).

\section{Echocardiography Analysis}

The echocardiography findings of the 18 patients with an echocardiography at 1 month are summarized in Table 3 . There was a statistically significant decrease in the peak (pretreatment $73 \pm 26 \mathrm{~mm} \mathrm{Hg}$ vs post-treatment $17 \pm 6$ $\mathrm{mm} \mathrm{Hg}$ vs 1 month $15 \pm 6 \mathrm{~mm} \mathrm{Hg}, P<.0001)$ and mean gradient (pretreatment $42 \pm 16 \mathrm{~mm} \mathrm{Hg}$ vs post-treatment $9 \pm 4 \mathrm{~mm} \mathrm{Hg}$ vs 1 month $8 \pm 3 \mathrm{~mm} \mathrm{Hg}, P<.0001$ ) after Edwards implantation, which was associated with an increase in the aortic valve area (pretreatment $0.72 \pm 0.21$ $\mathrm{cm}^{2}$ vs post-treatment $1.87 \pm 0.45 \mathrm{~cm}^{2}$ vs 1 month 1.81 $\left.\pm .32 \mathrm{~cm}^{2}, P<.0001\right)$. Ventricular function did not change significantly during follow-up. No difference was observed between patients treated through the TF or TA approach.

Before treatment, a significant AR was observed in 9 of 22 patients $(41 \%$, Table 1$)$. AR was mild, moderate, and severe in 5 patients $(23 \%), 3$ patients $(13 \%)$, and 1 patient $(5 \%)$, respectively. The degree of AR before and 1 month after Edwards SAPIEN valve implantation in the 18 patients with echocardiography follow-up is shown in Table 3 and Figure 2, A. Although a moderate to severe AR was observed in 4 of 18 patients $(22 \%)$ before treatment, it was no longer the case at 1 month $(P=.03$, Figure $2, A)$. The improvement was secondary to a disappearance of the AR in all 7 patients with a significant AR before treatment, whereas the new ARs appearing in 5 of the 11 patients with no AR at pretreatment were only mild (Table 4; Figure 2,B).

\section{DISCUSSION}

The present study is the first to show that in patients referred for TAVI for aortic stenosis, a simple prospective strategy of "oversizing" the implantation of the Edwards SAPIEN bioprosthesis may prevent the occurrence of moderate and severe ARs.

\section{Impact of "Oversizing" the Edwards SAPIEN Bioprosthesis on Aortic Regurgitation}

The key finding of this study is that the use of a simple "oversizing" policy was associated with no occurrence of moderate or severe ARs at 1 month with no case of rupture of the aortic annulus and no prosthesis-patient mismatch. This benefit was the result of 3 simple measures, including (1) exclusion of all patients with an aortic annulus greater than $24 \mathrm{~mm}$ by TEE during the screening process, (2) use of a $26-\mathrm{mm}$ prosthesis in all patients with aortic annulus greater than 21, and (3) use of a $26-\mathrm{mm}$ prosthesis in patients with an aortic annulus 21 or less whenever sizing based on balloon valvuloplasty with a $23-\mathrm{mm}$ balloon and contrast angiography suggested that it was feasible.

Our results are consistent with a recent retrospective analysis of determinants of AR after Edwards SAPIEN bioprosthesis implantation by Detaint and colleagues. ${ }^{3}$ They observed that oversizing the prosthesis, as estimated by the "prosthesis/annulus cover index," was the major factor associated with the absence of severe AR after implantation. Of note, in our population the cover index was twice as high as in the population studied by Detaint and colleagues $(12.4 \pm 4.3$ vs $6.7 \pm 4)$. Detaint and colleagues also found that a moderate to severe AR was never observed in patients with a "cover index" greater than 8 or an aortic annulus less than $22 \mathrm{~mm}$. Of note, this combination was present in 20 of 22 patients $(91 \%)$ in our population but in only half of the population studied by Detaint and colleagues. $^{3}$

Analysis of the respective role of the criteria used in the selection process demonstrates that the exclusion of patients with an annulus greater than $24 \mathrm{~mm}$ would have already resulted in a high cover index of $9.9 \% \pm 3.6 \%$. The use of the 2 additional criteria further increased the cover index of our population to $12.4 \% \pm 4.3 \%$.

The exclusion of patients with an aortic annulus greater than $24 \mathrm{~mm}$ is already recommended as a common practice. However, this rule is not strictly applied, and in a recently published series, Detaint and colleagues ${ }^{3}$ reported that an Edwards SAPIEN was implanted in patients with an annulus greater than $24 \mathrm{~mm}$ in more than one third of the cases. 


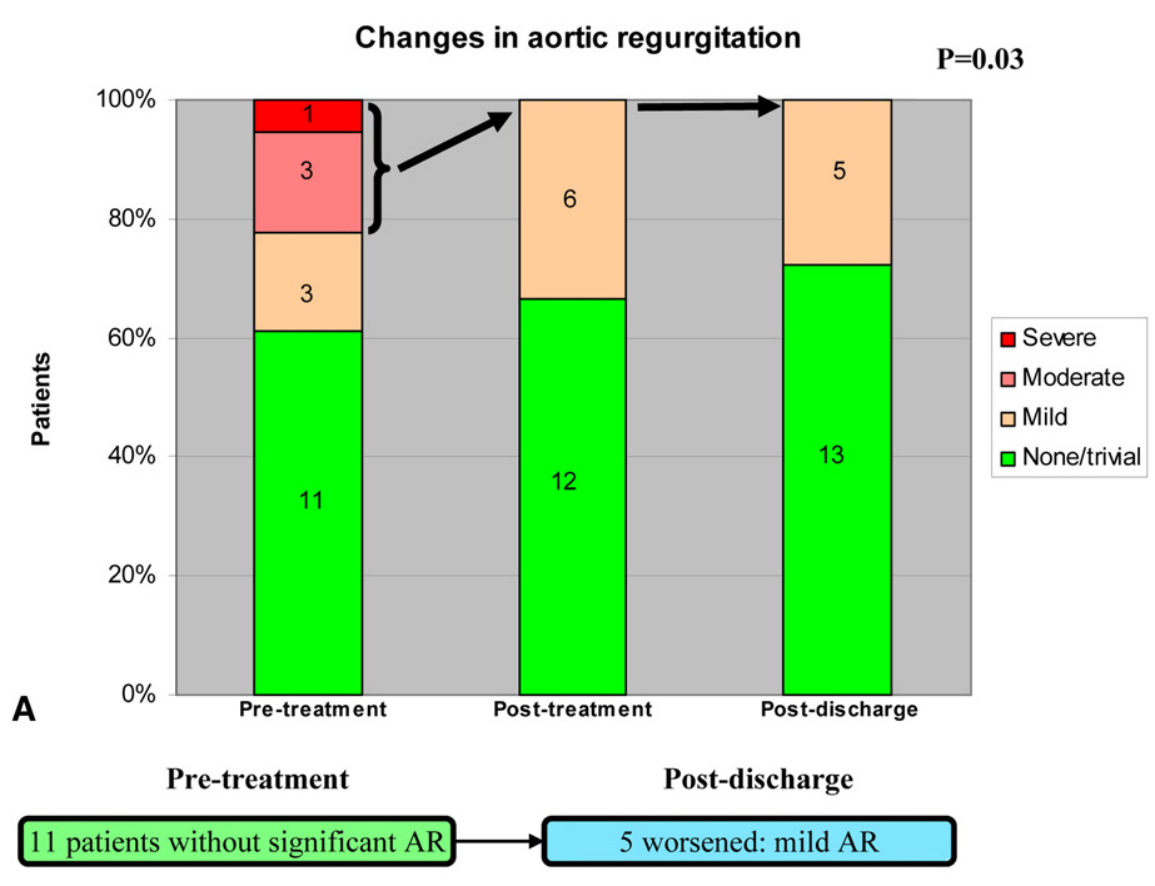

3 patients with mild AR $\rightarrow 3$ improved: no AR

3 patients with moderate AR $\rightarrow 3$ improved: no AR

1 patient with severe AR

1 improved: no AR

B

FIGURE 2. A, Changes in aortic regurgitation in the 18 patients with echocardiography follow-up $(P=.03$ by 1 -way repeated-measures Friedman test). $\mathrm{B}$, Individual changes in aortic regurgitation from pretreatment to postdischarge. $A R$, Aortic regurgitation.

In some cases, this is an unanticipated finding of the TEE performed at the time of the intervention in a patient in whom no TEE was performed during the screening process or there is no other option in this patient. In this context, our observation that 6 of 28 patients $(21 \%)$ were finally excluded on the basis of the TEE, whereas they were initially considered good candidates for the procedure based on TTE, advocates the systematic use of TEE as part of the screening process. This also strengthens the need for larger endoprostheses. The recent availability of the 29-mm Edwards SAPIEN endoprosthesis will allow this technology to be offered to patients with an aortic annulus greater than $24 \mathrm{~mm}$ without decreasing the "cover index" and taking the risk to induce a moderate or severe AR.

In addition, this approach was not associated with any stent deformation or prosthesis-patient mismatch as shown by the low transvalvular gradient $(8 \pm 3 \mathrm{~mm} \mathrm{Hg})$. This observation combined with the absence of aortic rupture in our series suggests that despite the presence of calcification, the aortic annulus keeps some of its ability to be stretched.

Our study also suggests that it might be important to switch from the TF to the TA approach in case an appropriately sized endoprosthesis cannot be delivered. Because the new device generation has been downsized, switching to the TA approach to accommodate the 26-mm bioprosthesis will be less frequent. This decision will remain critical in patients with an annulus diameter of approximately $24 \mathrm{~mm}$ in whom the choice to implant a $29-\mathrm{mm}$ bioprosthesis will imply the switch from the TF to the TA approach.

In our study, the increment of the intended size of the bioprosthesis after predilation combined with aortic angiography in 3 patients strengthens the importance of this step as the final critical step to size the annulus and to choose the appropriate diameter of the bioprosthesis. 
TABLE 4. Procedural approach for each patient and impact on aortic regurgitation

\begin{tabular}{|c|c|c|c|c|c|c|c|c|}
\hline \multirow[b]{2}{*}{ Gender } & \multicolumn{2}{|c|}{ Annulus diameter (mm) } & \multirow{2}{*}{$\begin{array}{l}\text { Femoral } \\
\text { approach } \\
\text { possible }\end{array}$} & \multirow{2}{*}{$\begin{array}{l}\text { Approach } \\
\text { used for } \\
\text { delivery }\end{array}$} & \multirow{2}{*}{$\begin{array}{l}\text { AR during balloon } \\
\text { inflation with a } \\
\text { 23-mm balloon }\end{array}$} & \multirow{2}{*}{$\begin{array}{c}\text { Edwards SAPIEN* } \\
\text { diameter }(\mathbf{m m})\end{array}$} & \multirow{2}{*}{$\begin{array}{l}\text { AR before } \\
\text { treatment }\end{array}$} & \multirow[b]{2}{*}{$\mathrm{AR}$ at $1 \mathrm{mo}$} \\
\hline & TTE & TEE & & & & & & \\
\hline Female & 19.9 & 20.6 & Yes & $\mathrm{TF}$ & No & 23 & Mild & None/trivial \\
\hline Male $\dagger$ & 21.5 & 21.9 & $22 \mathrm{~F}$ only & TA & No & 26 & None/trivial & None/trivial \\
\hline Female $\dagger$ & 22.9 & 23.5 & $22 \mathrm{~F}$ only & $\mathrm{TA}$ & Yes & 26 & None/trivial & None/trivial \\
\hline Female & 22.8 & 23.5 & Yes & $\mathrm{TF}$ & Yes & 26 & None/trivial & Mild \\
\hline Female & 19.8 & 20.3 & No & TA & No & 23 & None/trivial & NA \\
\hline Male & 22.9 & 23.5 & Yes & $\mathrm{TF}$ & Yes & 26 & None/trivial & Mild \\
\hline Male & 23.5 & 23.8 & No & TA & Yes & 26 & None/trivial & Mild \\
\hline Female $†$ & 20.2 & 20.8 & Yes & $\mathrm{TF}$ & Yes & 26 & Mild & None/trivial \\
\hline Male & 20.5 & 20.8 & No & TA & No & 23 & None/trivial & Mild \\
\hline Male & 22.5 & 22.9 & No & TA & No & 26 & None/trivial & None/trivial \\
\hline Male $\dagger$ & 20.1 & 20.7 & Yes & $\mathrm{TF}$ & Yes & 26 & Moderate & None/trivial \\
\hline Male & 22.8 & 23.6 & Yes & $\mathrm{TF}$ & Yes & 26 & Moderate & None/trivial \\
\hline Female & 20.4 & 21.0 & 22F only & $\mathrm{TF}$ & No & 23 & Mild & NA \\
\hline Female $\nmid$ & 20.9 & 21.4 & $22 \mathrm{~F}$ only & TA & No & 26 & Severe & None/trivial \\
\hline Female $†$ & 20.2 & 20.6 & No & $\mathrm{TA}$ & Yes & 26 & Moderate & None/trivial \\
\hline Male & 23.2 & 23.7 & No & $\mathrm{TA}$ & Yes & 26 & None/trivial & None/trivial \\
\hline Female & 19.0 & 19.9 & No & TA & No & 23 & None/trivial & None/trivial \\
\hline Male & 21.9 & 22.5 & No & $\mathrm{TA}$ & No & 26 & None/trivial & NA \\
\hline Male & 22.7 & 23.2 & No & $\mathrm{TA}$ & No & 26 & Mild & NA \\
\hline Female & 20.3 & 20.9 & $22 \mathrm{~F}$ only & $\mathrm{TF}$ & No & 23 & Mild & None/trivial \\
\hline Male & 23.0 & 23.4 & Yes & $\mathrm{TF}$ & Yes & 26 & None/trivial & Mild \\
\hline Female & 21.7 & 22.9 & Yes & $\mathrm{TF}$ & No & 26 & None/trivial & None/trivial \\
\hline
\end{tabular}

TTE, Transthoracic echocardiography; TEE, transesophageal echocardiography; $A R$, aortic regurgitation; TF, transfemoral; TA, transapical; NA, not available. *Edwards Lifesciences LLC, Irvine Calif. †Patients in whom the procedure was modified.

Although the strategy applied in our population was associated with no occurrence of moderate to severe AR, it did not prevent the occurrence of mild AR in 5 of 11 patients without AR at pretreatment. Further improvements in bioprosthesis design or implantation strategy are still needed to avoid this complication.

In this series, no event associated with the oversizing strategy was observed. In particular, no case of annulus rupture or stroke was observed. The rates of myocardial infarction $(4 \%)$ and heart block requiring pacemaker $(4 \%)$ are on par with those described in previous series and in the recently published PARTNER trial. ${ }^{16}$ Fluoroscopy and TEE performed at the end of the procedure did not show distortion of the struts of the stent. Likewise, TTE performed before discharge or at 1-month follow-up did not show high transvalvular gradient suggestive of prosthesis-patient mismatch.

Of note, in this series, a benefit on LV dimensions was observed as early as 1 month after the procedure. Although it takes several months to achieve near complete LV remodeling after conventional aortic surgery for aortic stenosis, ${ }^{17} \mathrm{se}-$ ries including early echocardiography follow-up after aortic replacement for aortic stenosis or aortic regurgitation demonstrated changes in LV dimensions within days of surgery. ${ }^{18,19}$ The results of our series in which no case of moderate to severe aortic regurgitation was observed postprocedure are consistent with those previous observations. In addition, the disappearance of moderate to severe aortic regurgitation that was present at pretreatment in approximately $25 \%$ of our patient population may have played a role.

\section{Study Limitations}

This was a single-center study, and patient referral and medical management may have influenced the results. However, the prospectively designed nature of our policy of "oversizing" the implantation of the Edwards SAPIEN bioprosthesis, the consecutive nature of the population, and the individual patient analysis of the serial echocardiography follow-up provide useful insights into the benefit of TAVI with the Edwards SAPIEN valve on aortic regurgitation. The lack of information on wall thickness and myocardial mass and the lack of a longer echocardiography follow-up may limit the interpretation of the benefit of the strategy on LV remodeling. Finally, although no event related to the oversizing strategy was observed, we must acknowledge that the number of patients included in the present study is too small to draw a definite conclusion on the safety of this approach.

\section{CONCLUSIONS}

On the basis of an individual and serial patient analysis, the present report provides important information on the 
outcome of AR after implantation of an Edwards SAPIEN valve in the aortic position. In particular, the results suggest that a simple "oversizing" policy may prevent the occurrence of moderate and severe ARs. Although these findings need confirmation in studies including more patients and with a longer follow-up, they support the use of larger endoprostheses $(29 \mathrm{~mm})$ to adequately treat patients with an annulus greater than $24 \mathrm{~mm}$.

\section{References}

1. Sun JC, Ghanta RK, Davidson MJ. Highlights from the transcatheter cardiovascular therapeutics conference 2010: Washington, DC, September 21-25, 2010. J Thorac Cardiovasc Surg. 2011;142:468-71.

2. Higgins J, Ye J, Humphries KH, Cheung A, Wood DA, Webb JG, et al. Early clinical outcomes after transapical aortic valve implantation: a propensity-matched comparison with conventional aortic valve replacement. J Thorac Cardiovasc Surg. 2011;142:e47-52.

3. Detaint D, Lepage L, Himbert D, Brochet E, Messika-Zeitoun D, Iung B, et al. Determinants of significant paravalvular regurgitation after transcatheter aortic valve: Implantation impact of device and annulus discongruence. JACC Cardiovasc Interv. 2009;2:821-7.

4. Moss RR, Ivens E, Pasupati S, Humphries K, Thompson CR, Munt B, et al. Role of echocardiography in percutaneous aortic valve implantation. JACC Cardiovasc Imaging. 2008;1:15-24.

5. Takagi K, Latib A, Al-Lamee R, Mussardo M, Montorfano M, Maisano F, et al. Predictors of moderate-to-severe paravalvular aortic regurgitation immediately after CoreValve implantation and the impact of postdilatation. Catheter Cardiovasc Interv. 2011;78:432-43.

6. Webb JG, Pasupati S, Humphries K, Thompson C, Altwegg L, Moss R, et al. Percutaneous transarterial aortic valve replacement in selected high-risk patients with aortic stenosis. Circulation. 2007;116:755-63.

7. Descoutures F, Himbert D, Lepage L, Iung B, Detaint D, Tchetche D, et al. Contemporary surgical or percutaneous management of severe aortic stenosis in the elderly. Eur Heart J. 2008;29:1410-7.

8. Vahanian A, Alfieri O, Al-Attar N, Antunes M, Bax J, Cormier B, et al. Transcatheter valve implantation for patients with aortic stenosis: a position statement from the European Association of Cardio-Thoracic Surgery (EACTS) and the European Society of Cardiology (ESC), in collaboration with the European As- sociation of Percutaneous Cardiovascular Interventions (EAPCI). Eur Heart J. 2008;29:1463-70.

9. Cribier A, Eltchaninoff H, Tron C, Bauer F, Agatiello C, Nercolini D, et al. Treatment of calcific aortic stenosis with the percutaneous heart valve: mid-term follow-up from the initial feasibility studies: the French experience. J Am Coll Cardiol. 2006;47:1214-23.

10. Walther T, Simon P, Dewey T, Wimmer-Greinecker G, Falk V, Kasimir MT, et al Transapical minimally invasive aortic valve implantation: multicenter experience. Circulation. 2007;116:I240-5

11. Tzikas A, Piazza N, van Dalen BM, Schultz C, Geleijnse ML, van Geuns RJ, et al Changes in mitral regurgitation after transcatheter aortic valve implantation. Catheter Cardiovasc Interv. 2009;75:43-9.

12. Oh JK, Taliercio CP, Holmes DR Jr, Reeder GS, Bailey KR, Seward JB, et al. Prediction of the severity of aortic stenosis by Doppler aortic valve area determination: prospective Doppler-catheterization correlation in 100 patients. J Am Coll Cardiol. 1988;11:1227-34.

13. Vahanian A, Baumgartner H, Bax J, Butchart E, Dion R, Filippatos G, et al. Guidelines on the management of valvular heart disease: the task force on the management of valvular heart disease of the European Society of Cardiology. Eur Heart J. 2007;28:230-68.

14. Zoghbi WA, Enriquez-Sarano M, Foster E, Grayburn PA, Kraft CD, Levine RA et al. Recommendations for evaluation of the severity of native valvular regurgitation with two-dimensional and Doppler echocardiography. J Am Soc Echocardiogr. 2003; 16:777-802.

15. Helmcke F, Nanda NC, Hsiung MC, Soto B, Adey CK, Goyal RG, et al. Color Doppler assessment of mitral regurgitation with orthogonal planes. Circulation. 1987;75:175-83.

16. Leon MB, Smith CR, Mack M, Miller DC, Moses JW, Svensson LG, et al. Transcatheter aortic-valve implantation for aortic stenosis in patients who cannot undergo surgery. N Engl J Med. 2010;363:1597-607.

17. Yarbrough WM, Mukherjee R, Ikonomidis JS, Zile MR, Spinale FG. Myocardial remodeling with aortic stenosis and after aortic valve replacement: mechanisms and future prognostic implications. J Thorac Cardiovasc Surg. 2011 Jul 13 [Epub ahead of print].

18. Petrov G, Regitz-Zagrosek V, Lehmkuhl E, Krabatsch T, Dunkel A, Dandel M, et al. Regression of myocardial hypertrophy after aortic valve replacement: faster in women? Circulation. 2010;122:S23-8.

19. Carroll JD, Gaasch WH, Zile MR, Levine HJ. Serial changes in left ventricular function after correction of chronic aortic regurgitation. Dependence on early changes in preload and subsequent regression of hypertrophy. Am J Cardiol. $1983 ; 51: 476-82$ 